tion of the lungs, occasioned by the inhalation of chloroformappear to be, 1st, that the appearances observed were those of asphyxia; 2ndly, that they were not such as are produced by chloroform, because in animals poisoned by chloroformvapour the blood is coagulated in the right side of the heartin asphyxia, fluid; and that reddening of the epiglottis is a sign of asphyxia, not of chloroform poisoning; and that the brain is not congested in chloroform poisoning, but is so in asphyxia.

I shall relate the principal facts observed in some recent experiments, without stating everything observed.

In the presence of $\mathrm{my}$ friend $\mathrm{Mr}$. Sheill, I poisoned a terrier dog with chloroform-vapour, and drowned another. I also performed a similar experiment upon two rabbits.

The chloroformed dog inhaled the chloroform from a kind of nozzle, open at the end, where there was a sponge impregnated with chloroform. Death could not take place from mere want of air. He appeared pretty nearly dead in two minutes and a half, but all signs of life were extinct within seven minutes. The symptoms were, at first, considerable struggling and a little wheezing, violent and irregular motion of the heart; then, forcible action of the abdominal muscles, stertorous breathing, loss of power over the limbs, and discharge of urine and freces; heart's action very feeble, pupils much dilated. All this applies to the first two minutes and a half. During the remaining period, a slight movement of the respiratory muscles was all that could be observed.

The drowned dog struggled under water for about two minutes.

On inspection after the interval mentioned, both dogs were stiff, and limbs extended, pupils in the drowned more dilated.

In the chloroformed the blood was almost quite fluid in the large veins; heart distended with dark blood, mostly coagulated in both its cavities; the left lung (the animal had been laid on its left side) was especially congested, it was enormously so; the other lung was also very much congested, but the left was in some places like liver. Both lungs were mottled and full of blood; some bloody froth was found in the bronchi; the trachea and larynx, also the epiglottis, redder than natural.

In the drowned, the blood was more coagulated in the great veins, but less so in the heart, than in the chloroformed; but the blood was by no means quite fluid in the heart. It was rather of a treacly consistence, very dark, and there were numerous coagula-very little blood on the left side. The lungs were congested in a very different manner from what appeared in the chloroformed dog. They were certainly much congested, but the congestion was more livid, not so florid; in patches, not uniform; and there was much froth, and apparently water, in the lungs. The larynx and epiglottis were not so vascular. Soot arising from the rain-water in the tub in which the drowning was effected, could be traced distinctly in the larynx and in to the lungs.

The abdominal organs were rather congested in both cases; the bladder, empty in the chloroformed, contained a little water in the drowned; the membranes of the brain and organ itself more vascular in the chloroformed.

In experiments by Orfila, on corpses placed in water in which animal charcoal was mixed, the charcoal was found in the air passages and lungs.-Traité de Medecine Legali, t.ii. 3rd ed., p. 385 .

That the blood is not necessarily fluid in the heart in asphyxia produced by drowning, is shown by the observations of Lafosse and Avisard, stated by Orfila. (ibid. p. 391.) " Lafosse found the blood polypous and concrete in some drowned persons. We have found in reality, once only, some fibrinous clots in the blood of a drowned person, and M. Avisard says that he has seen it coagulated or semi-coagulated in the right auricles and ventricles of two individuals drowned while living." In a rabbit which I drowned, the blood, twenty-four hours after death, was found in solid coagulated masses, both on the right and left sides of the heart (auricles and ventricles) and in large veius. At the time when I drowned this rabbit, $\mathrm{I}$ also chloroformed another, in the presence of $\mathrm{Mr}$. Sheill, (who also saw both rabbits opened.) It was killed in a few seconds, apparently as speedily as by prussic acid; the principal differences were the following: the blood was more solid in the drowned; the lungs presented appearances similar to those observed in the dog's; the larynx, trachea, brain and its membranes, much more vascular in the chloroformed.

In another very strong dog, which I killed with the vapour of chloroform in about fifteen minutes, on immediate inspection the same enormous congestion of the lungs was observed; congestion of the brain, much serum in the ventricles, very considerable reddening of the larynx, trachea, and epiglottis; irritability of the voluntary muscles diminished, peristaltic action went on. Heart enormously distended with dark fluid blood, principally on the right side; its irritability destroyed.

No inference can be drawn from the state of the abdominal organs as to the cause of death by chloroform or ordinary asphyxia.

In Dr. Jamieson's case at Aberdcen, the post-mortem appearances were essentially similar to those observed in the case of Hannah Greener; also in the recent case of poisoning by ether in France. What they were in the fatal case at Birkenhead does not yet appear, but death seems to have been produced by pulmonary apoplexy. According to Dr. Simpsou's explanation of the Aberdeen case, as given in the Scotsman, the person contrived to fall forward on a wet towel (wet, too, by a volatile fluid,) so cleverly, as to seal hermetically both nose and mouth !

I agree with Dr. Jamieson, that the subject of his paper died from asphyxia produced by chloroform. No doubt the appearances which occur in chloroform poisoning are very similar to those produced by ordinary asphyxia, (speaking generally;) but there remains the difference in the character of the pulmonary congestion. But I believe that chloroform may kill by syncope, by its effect in stopping the heart's action, when we may have no congestion of the lung. With regard to Professor Simpson's assertion, that the blood is always coagulated in the heart in death from chloroform, fluid in asphyxia, we see that it is neither uniformly fluid nor uniformly solid in either case. It was fluid in Dr. Jamieson's case, and in the recent fatal ether case in France.

Professor Simpson's assertion, that reddening of the larynx and epiglottis, and congestion of the brain, do not occur in chloroform poisoning, is shown to be erroneous.

Two other arguments require to be stated against Professor Simpson's assertions.

He makes out, I think, that Hannah Greener was hardly properly under the influence of chloroform. But if this were the case, how came the reflex phenomena of both larynx and pharynx to be destroyed? which would necessarily be the case according to the Professor's view of the cause of death. This argument has been touched on by a recent correspondent of The Lancet. Or how could, as Dr. Meggison observes, even choking produce such enormous congestion of the lungs when the heart was not acting?

Sir John Fife and I were of opinion that the congestion of the lung was the cause of death, because it was so enormous as to cast every other post-mortem appearance into the shade

Of the power of chloroform to produce this congestion, I warned the profession in a letter, published in the Medical Gazette of December 3rd, when all was couleur de rose concerning chloroform; and the experiments of Mr. Wakley \&c. have abundantly established the reality and formidable nature of this power. Nevertheless, I give no opinion as to the use of chloroform. I believe it to be both more powerful and more dangerous than ether. In a recent case here of a formidable character, I advised a friend to use it. We could hardly expect so great a boon as the removal of pain in surgical operations without a per contra.

Newcastle-on-Tyne, 1848.

\section{FURTHER OBSERVATIONS ON THE EMPLOY. MENT OF CHLOROFORM IN PARTURITION.}

\section{By ROBERT BARNES, M.B., London.} LECTURER ON MIDWIFERY.

An attentive observer of passing events cannot fail to anticipate that Dr. Simpson's prophecy as to the approaching universal employment of chloroform in obstetric practice will turn out abortive. In the midst of the most glowing and hyperbolical praises of the virtues of this intoxicating agent in parturition, and the imperfect details of labours conducted under its influence, which crowd upon the medical journals, there ooze out, now and then, sundry ominous mishaps : and such opposite and contradictory results are said to follow its use, that the mind is lost in the endeavour to reconcile them, or to ascertain what effects the anæsthetic or "meddling" school of midwifery would really wish to assign to it.

Are the labour-pains too strong,-do they threaten laceration of the perinæum? Chloroform is given, and the pains are subdued exactly to the point desired to effect delivery and avert laceration. Is the labour lingering from inefficient uterine action? Chloroform is given, and the pains immediately increase. Is the labour retarded by the rigidity of the soft parts? Chloroform is inhaled, and relaxation ensues in a " magical" manner. Does any one imagine that relaxation is not 
desirable? Let him be reassured, for a gentleman tells us that "the parts under its use continue unaffected by it." If we believe all we read of reported cases, chloroform is the grand obstetric Caducens. In difficult parturition, no operation can be so properly performed without its grateful aid ; in ordinary parturition, Nature herself must not presume to accomplish her own ends, unless modified and controlled by this omnipotent vapour.

When, in a former paper, I asked what warranted Dr. Simpson in using so powerful an agent in natural labour, $I$ was triumphantly answered that the professor had tried it on himself! I might object that the professor was not in labour, and that this was another instance of false analogy. The eleven cases of chloroformization Dr. Simpson detailed in his original proclamation, I did not think of a nature to justify his encominms. The remainder of his arguments, statistical, analogical, and minatory, crumbled before the touchstone of reason; and no one has since endeavoured to reconstruct them. Facts were required; and now that facts have come forth, let us see what they teach us.

It may be as well, however, to bear in mind that the great majority of the cases hitherto reported bear the impress of preconceived judgment in favour of chloroform. They are mostly related by those who are enraptured with its powers. We must not, therefore, wonder that we have no report of any formidable accident under its nse. An unfavourable case of midwifery brought about by interference is too serious a thing to publish. The courage of most men is not equal to the task. I fear I cannot join in the hope so well expressed by Mr. Selby, "that we are not presented with the fair side of the picture, while the darker and more forbidding shades are studiously concealed." It is a remarkable fact, that while almost all that we read of the powers of chloroform is eulogistic, almost all that we hear is condemnatory.*

The reported cases, then, must be received with some grains of allowance. Mr. Lansdown has never observed the perinæum to be relaxed by chloroform, "the parts under its use continuing unaffected by it." (THE LANCET, Jan. 1, 1848.)

Mr. Parsons and others affirm that decided relaxation of the soft parts was produced. (THE LANCET, March 4, 1848.)

In one case in which Mr. Lansdown kept the patient under the influence of chloroform and ether for sixteen hours, "he almost fancied it arrested the action of the uterus :" at any rate, he finished the labour by the forceps without the knowledge of the mother. Mr. Fairbrother says, in one case, on administration of chloroform, "the pains became less frequent" and "diminished in intensity." (THE LANCET, January 8, 1848.)

Dr. Tyler of Dublin has related a case in which the pains were twice arrested after inhalation of chloroform, returning as the influence of the chloroform subsided.

Dr. Henry Bennet says, in one of his cases "the pains became less frequent, less intense, but more uterine." The same writer, in illustration of this property, relates a case, having the following somewhat startling heading : "first labour; patient muscular and robust ; wide pelvis ; impending rupture of perinæum, owing to violent uterine contractions, prevented by chloroform." A calm and rational scepticism might ask for the evidence that rupture of the perinæum was impending, and doubt that chloroform prevented it. If negative and hypothetical evidence of this kind were freely admitted, the supremacy of chloroform in all obstetric difficulties might soon be established. We have only to picture to ourselves, in any given case of labour, that some formidable accident, such as rupture of the uterus or perinæum, convulsions, syncope, hæmorrhage, or death from exhaustion is impending, to give chloroform : and then, if the dreaded phantom does not appear, to conclude that chloroform averted it.

On the other hand, Mr. Brown says, "He thinks he can show that chloroform will not only produce insensibility to pain, but in certain lesser doses produces expulsive pains." In one case he advances, in support of this doctrine, the patient "begged to be allowed to take some ergot." Mr. Brown "accordingly gave her a drachm of it." In an hour after this, he administered chloroform. "In ten minutes, pains came on gradually, and yet with good expulsive power." "Where ergot had been given, it is clearly unphilosophical to draw the conclusion that chloroform produced expulsive pains. In the other case, (a footling presentation,) after giving chloroform, Mr. Brown says he "brought down" the body, the shoulders, both arms and head successively. Surely enough to excite expulsive pains! (The LaNCET, January 22.)

* The editor of the Medical Gazette, says, "W We heard of a case som weeks since, in which chloroform was used, and there was great reason to believe that it proved fatal. On application, the parties declined to publis he particulars !"
Mr. Brown, in another place, says he had found the chloroform always produce expulsive pains of the uterus. (THE LANCET, Jan. 15, 1848.)

Mr. Brown, after praising the use of chloroform in natural labour, "thinks it behoves every one who has fairly tried it to come forward and state his opinions." It would be more to the purpose if every one would come forward and state his facts.

Mr. Selby relates a case in which alarming syncope was produced by forty minims of chloroform.

Dr. Henry Bennet has " in several instances seen its effects followed, for two or three days, by extreme muscular debility, and nervous irritation."

Other cases of most alarming prostration of the vital powers are related; and also of violent convulsions accompanied with obvious cerebral congestion. On the other hand, chloroform is reported by Mr. Fearn (Medical Gazette, Feb. 11) to have had good effect in subduing convulsions. Unfortunately, no conclusion can be drawn from this case, as his patient had been previously bled. Dr. Henry Bennet again says, that "general congestion and maniacal excitement were at once subdued by chloroform."

We have evidence, then, that chloroform arrests uterine action; that it increases uterine action: we have evidence that it causes relaxation of the os uteri and perinæum; and that the parts continue unaffected by its use. We have evidence that it produces alarming syncope, congestion, and convulsions, and yet that it cures convulsions and cerebral congestion. Such conflicting testimony is extremely embarrassing: it compels us to suspend our judgment as to what are the real effects of chloroform in labour. It is sufficient, however, to furnish a useful text for some practical remarks. Chloroform increases expulsive pains, or it diminishes them.

To take the first case. If the uterine contractions are increased, what is the consequence? It is fair to assume, what universal experience has proved, that in the vast majority of cases the unaided contractions of the uterus are adequate to effect the safe delivery of the child. If the contractions in cases of natural labour are artificially increased, $a$ priori, then we cannot avoid the conclusion that greater contraction than is beneficial is produced. If we have to deal with a case of obstructed delivery from malposition or disproportion, then the increased contractile energy of the uterus would be manifestly dangerous, and chloroform must be discarded in this case for the same reason as ergot of rye. If the contractile energy is increased beyond the natural extent, then we also run increased hazard of inducing puerperal convulsions and lacerations.

Take the second case. If the uterine contractions are enfeebled or arrested, what is the inevitable consequence? Either that the mother and child must encounter all the perils of protracted labour, or artificial interference must be resorted to. In illustration, we are furnished with a case in point. Mr. Lansdown "almost fancied chloroform and ether arrested the action of the uterus;" at any rate, he felt the necessity of delivering by the forceps, which he did without the knowledge of the mother. Within the limits of five weeks, also, Mr. Wilton (Tre Lancex, March 4, 1848) felt the necessity of using the forceps three times, on two of which occasions chloroform was employed. It is but fair to Mr. Wilton to suppose that chloroform had some influence in inducing this necessity, when we reflect upon the following opinion of Dr. Joseph Clarke concerning instrumental labour: "Cases of convulsions excepted, I have rarely had occasion to be pleased with the effect of extracting instruments, and not unfrequently have I had much reason to deprecate their evil consequences. Whenever labour is protracted to a dangerous length, by unusual resistance, there is nothing but mischief to be apprehended from their application, but when the expelling powers are impaired by debilitating diseases, the interposition of an artificial extracting power is more rational and justifiable. Let it be remembered that in the hospital such means were employed in one of 728 cases; and in private practice, it is so long since $I$ have had occasion to use or even to think of using them, that I am persuaded a fair opportunity of applying forceps with good effect will not occur to a rational practitioner in one of 1000 cases."

If, then, anzesthetic agents increase the occasions for having recourse to the forceps, as there is but too much reason to fear they do, there will be established in that fact a most fatal objection to the indiscriminate use of chloroform. Who will not shudder for the dangers uuhappy women are henceforth doomed to encounter at the hands of those to whom they look for relief, if the use of chloroform is to become universal

It has been hinted that anasthetic agents will furnish to 
"the unscrupulous a ready means of perpetrating their deeds of darkness." I will not dwell upon this objection, because I think it unfair to argue against a remedy on the ground of the abuses to which unprincipled persons may apply it. Such an objection would be out of place when addressed to the practitioners of medicine. But I fear we shall hardly be justified in concluding that these agents are altogether safe from some kind of abuse even in the hands of legitimate practitioners. There arise in practice frequent temptations to expedite delivery by the forceps; and when one great objection to their use, the pain apt to be inflicted, is removed, we cannot resist the conviction that they will often be resorted to unnecessarily. The sensitive mind shrinks from contemplating the mischiefs that will result. In Great Britain one mother in twenty dies under the forceps, and more than one child in five; to say nothing of lacerations, contusions, and other deplorable evils.-(Churchill.)

Because I demurred to accepting the arguments advanced by Dr. Simpson in favour of the use of chloroform in natural labour, the stupid charge of "inhumanity" has been directed against me. It remains to be proved whether the interest of "humanity" sanctions the general employment of chloroform in midwifery, or whether it does not emphatically condemn it. On this subject I cannot better express my own feelings than in the words of one of the most reflective writers of the present day-my colleague, Dr. Tyler Smith. The quotation is as applicable now to chloroform as it was a year ago to ether. "More recent experience has certainly not been in favour of enlarging the limits of its applicability in practical midwifery. In our own department there is good reason to believe, that after a short time, unless some certain mode of binding or disciplining this Prometheus shall be discovered, it will be rarely, if ever, used in difficult parturition or obstetric operations, and certainly never in natural labour. It will be a disappointment to have to turn from this promised good; but it is better to do so than to follow an ignis fatuus, if so it prove, to the neglect of real and scientific advancement. Let us hope that this glimpse of deliverance from this heavy infliction on humanity may act as a stimulus to Science to continue her search after some certain and available relief from physical pain, possibly a visionary search, but still one for which human nature will never cease to yearn."**

Having discussed one or two objections which have struck me on perusal of reported cases, I will avail myself of this opportunity to protest against the unfair treatment to which Dr. Meggison has been exposed in some recent comments upon the late fatal case at Newcastle. There is no part of Dr. Henry Bennet's paper which has given me more pain than that in which, falling into error as to facts, he abets Dr. Simpson in inflicting a great injustice on a brother practitioner. Dr. Simpson, with more ingenuity than success, laboured to show that Dr. Meggison's patient " did not die from the effects of chloroform, but from the effects of the means used to revive her." In other words, that Dr. Meggison killed his patient by improper interference. Dr. Bennet pleads for the credit of chloroform at the expense of Dr. Meggison in a similar manner, but makes him destroy his patient by different means. It appears to Dr. Bennet that the fatal event was probably owing to the neglect of the precautions of using a thin pocket handkerchief for the chloroform, and allowing the patient occasionally to breathe atmospheric air. Assuming that the chloroform was poured upon a table-cloth, and that this was kept closely in contact with her mouth and nostrils, Dr. Bennet infers that death was principally owing to asphyxia caused by the want of oxygen in the lungs. An appeal to the elements of physiology will expose the absurdity of Dr. Simpson's attempted exculpation of chloroform; an appeal to facts will set aside Dr. Bennet's. John Payne deposed at the inquest as follows:- "Dr. Meggison held a pocket-handkerchief to her mouth and nose; he kept it moving at times." An appeal to common sense will confirm the verdict of the jury founded on the competent evidence of Sir John Fife and Dr. Glover, that the "deceased died from congestion of the lungs produced by chloroform."

It is surely riding a hobby somewhat too hard, when all its mishaps are saddled on those who use it. The history of this unfortunate case may, however, furnish a useful lesson to those who are inclined to submit their judgments to the new obstetric dictator. Should they, governed by his authority, rashly adopt his practice, and, disappointed in the results, be visited with public censure, let them not hope that Dr. Simpson will come forward to protect them. He will direct against them individually the blame that should be imputed to his

* Lecture on Inhalation of Ether in Qustetric Practice, The LANcer, March 27th, 1847. own advice. While listening to Dr. Simpson's persuasions to use chloroform in every case of natural labour, it should be remembered that his credit is pledged to its universal adoption. Before the result of twelve cases was known to him, he had already drawn the conclusion, that it ought to be resorted to in every case of natural parturition. He had enforced his own premature conviction, by declaring that medical men may oppose for a time the superinduction of anssthesia in parturition; but they will oppose it in vain, for certainly our patients themselves, and their friends, will force the use of it upon the profession." The profession may rest assured that this argumentum ad crumenam is no better founded than Dr. Simpson's other arguments. The almost universal feeling of the well-educated women of this country is resolutely opposed to the idea of abandoning the highest prerogative bestowed upon mankind, for the sake of tiying from physical pains when by so doing they may heedlessly run into other and more serious evils that they know not of.

Gloucester-terrace, Hyde-park, 1848.

\section{ASIATIC CHOLERA: ITS PATHOLOGY AND} TREATMENT.

By E. V. MLAINWARING, M.D., Bournemouth.

WrTh your permission, I will answer Dr. Armstrong's letter, he having mistaken the effect of disease for a cause.

His letter in The Lancet (p. 375) says: "The black blood in cholera is probably caused by the spasm of the diaphragm and other muscles of respiration preventing the lungs from carrying on their functions, and consequently impeding the process of arterialization."

I will ask the doctor how he accounts for the "spasm of the diaphragm and other muscles"? If it be not produced by a poisonous gas, by what is it produced?

The doctor seems to despise tartarized antimony as a remedy in cholera; but as I have observed undoubted good effects from its use, I do not hesitate to recommend the treatment to others, even as a sedative. Tartar-emetic may relieve the "spasm of the diaphragm and other muscles."

The counter-irritation, opium, and stimulants, with one or two moderate doses of calomel-treatment which Dr. Armstrong prefers - I have known to fail in more instances than one.

The doctor says, "as far as his experience goes, Asiatic cholera is no respecter of persons." In this country it appears to have been more discriminating, its attacks being principally to the ill-fed, ill-lodged, and intemperate portion of confined the inhabitants.

The cholera in India, being more general in its attacks, may be accounted for by observing that the towns and cities are generally built on swampy ground, and near large rivers having inefficiently ventilated houses and streets, with bad drainage-a combination of evils, in a hot climate, enough to affect the high and the low, the rich and the poor; and if we take into consideration the enervating habits of the higher classes in India, it will be easily understood why " cholera is no respecter of persons" in that country. An individual may be "a regular liver," as far as eating and drinking are concerned, but eating and drinking are not the only causes of debility, and consequently are not the only evils to be avoided. A ride in the hot sun, distress of mind, over-exertion, \&c., or a single excess of any kind, will produce a liability to the dis. ease when the poison is rife in the air.

In conclusion, I beg to observe, that the treatment mentioned in a former paper having proved successful in this country, it is its best recommendation; and in the event of a recurrence of the Asiatic cholera, I think it deserving a faiz trial.

Bournemouth, Hants, 1848.

\section{ON A NEW PRINCIPLE IN THE TREATMENT} OF ASPHYXIA FROM SUBMERSION IN WATER OR PURE CARBONIC ACID.

By WILLIAM REID, M.D., Liverpool.

I BEG leave to suggest, as an improvement in the method of treating the apparently asphyxiated from submersion, the admixture of a certain anıunt of chlorine gas, or perhaps nitrous oxide-though I would give the preference to the formerwith the atmospheric air used in insufflation of the lungs, or artificial respiration This $I$ am led to propose, on the prin- 